\title{
A Novel Model to Predict Academic Satisfaction on Scientific Research Among Medical Postgraduates in China: a Cross-Sectional Study
}

\section{Ting Luo}

Second Xiangya Hospital of Central South University

\section{Mengyuan Yang}

Second Xiangya Hospital of Central South University

\section{Yongxiang Wang}

Second Xiangya Hospital of Central South University

\section{Fei Guo}

Second Affiliated Hospital of Air Force Medical University

\section{Peng Mei}

Second Xiangya Hospital of Central South University

\section{Shengyang Jin}

Chinese Academy of Medical Sciences and Peking Union Medical College

\section{Xiaohui Xie}

the Tongji Hospital Research Building, Huazhong University of Science \& Technology

\section{Yiling Ding ( $\sim$ dylcsu@sina.cn )}

Second Xiangya Hospital of Central South University

\section{Mingxing Lei}

Hainan Hospital of Chinese PLA General Hospital

\section{Research Article}

Keywords: Academic satisfaction, Chinese universities, projects participated, studied extensively

Posted Date: September 17th, 2021

DOI: https://doi.org/10.21203/rs.3.rs-883130/v1

License: (c) (1) This work is licensed under a Creative Commons Attribution 4.0 International License. Read Full License 


\section{Abstract}

Academic satisfaction with scientific research is an important reflection of whether the process or result of academic research meets researchers' expectations. However, the status quo and associated factors among medical postgraduates have not been studied extensively. We carried out a cross-sectional study. This study was based on an online questionnaire that was designed and extended to medical postgraduates in hospitals affiliated with Chinese universities between November 12, 2020, and January 12, 2021. An 11 Likert scale (from 0 to 10) was used to measure self-satisfaction, and the mean score among academic masters, professional masters and doctors was 4.43, 3.70 and 4.65, respectively. For a total of 1067 medicine participants, low academic satisfaction significantly correlated with depression or anxiety. Research learning manner of self-learning without guidance is another important risk factor $(\mathrm{OR}=1.88)$. Medical school year of training, number of projects participated, research working time per day and marital status are other considerable associated factors but less association between papers and satisfaction. The results suggested that academic satisfaction among medical postgraduates improves with the guidance and projects participated. Assessing low satisfaction early and intervention measures are needed to improve academic satisfaction, especially for master candidates.

\section{Introduction}

Academic satisfaction with scientific research is an emotional situation regardless of whether the process or result of academic research meets researchers' expectations. High academic satisfaction contributes to promoting the psychological health of students, maintaining interest and enthusiasm in academic studies, facilitating the effectiveness of daily work and strengthening the belief that individuals can perform the career process successfully ${ }^{1}$. Tabbodi and colleagues have indicated a meaningful correlation between well-being and the progress of students ${ }^{2}$. However, mounting evidence suggests that practicing doctors are increasingly dissatisfied, unhappy and burnout ${ }^{3,4}$. In various countries, medical students, these soon-to-be doctors, are also subject to significant stressors and already demonstrate high levels of burnout ${ }^{5-7}$. However, the status quo and associated factors of the academic satisfaction of medical postgraduates have not been studied extensively.

Medical postgraduates are expected to be the next generation of excellent health care professionals ${ }^{8}$. After the publication of the development strategy of China's degree and postgraduate education (2002$2010)^{9}$ and the "two track integration" mode $(2013)^{10}$, medical postgraduates have undergone bidirectional clinical and scientific research development over the past decade. Meanwhile, professional medical degrees and academic medical degrees developed into main degree categories in China. More specifically, professionals are required not only to accomplish degree theses but also to cycle around different departments for the standardized training of residents during the period of education. Departments' rotation is not mandatory for academic departments, while their graduation needs a higher qualified degree thesis based on original scientific research. Furthermore, medical masters are more likely to enroll in doctor education if they have published papers included in the Science Citation 
Index. The research time and environment seem very different among academic and professional postgraduates. The majority of medical postgraduates, especially professional postgraduates, as clinicians and researchers take heavy workloads in a tight time. However, it is rarely reported whether satisfaction differs in medical postgraduates of different degree categories and whether the number of published papers or participating projects is associated with satisfaction. Moreover, postgraduates may counter various objective challenges, including insufficient guidance, nonstandard scientific research laboratories and research funding shortages. These challenges might lead to academic pressure, poor performance and mental health problems ${ }^{11,12}$, which would in turn impact satisfaction.

Scientific research has become a crucial and indispensable part of postgraduates' education, but some of them feel stressful and depressed during the period of academic study. According to a large metaanalysis, the prevalence of depression or depressive symptoms among 129,123 medical students was $27.2 \%$, which was higher than that reported in nonmedical students (range, $13.8 \%-21.0 \%)^{13-15}$ and in the general population of similar age (range, 5.8\%-9.3\%) ${ }^{16}$. Additionally, the prevalence of suicide among medical students was three times that of other educational settings ${ }^{13,17}$. Academic satisfaction, as a subjective diagnosis, may also be directly influenced by personality. One investigation demonstrated that personality traits were critical in determining work values ${ }^{18}$. The sense of time urgency is a component of the Type A behavior pattern (TABP) ${ }^{19}$. Under this feeling, people pay continuous attention to time and believe that the task must be completed in a hurry, which exerts pressure on medical students and leads to anxiety or depression ${ }^{20-23}$. Consequently, these psychological issues can lead to poor academic performance ${ }^{24}$. However, whether those mental unhealthy are subjective factors relating to satisfaction has not yet been verified.

Exploring self-satisfaction and its influencing factors on medical postgraduates will help mentors and hospital administrators better understand the self-satisfaction of students and give them tangible targets for developing effective interventions. In this study, we are interested in the state and factors associated with self-satisfaction with scientific research among professional and academic medical postgraduates. We sought to determine the following research questions: (1) the level of self-satisfaction of medical postgraduates in different degree categories; (2) the factors associated with self-satisfaction among those populations; and (3) how to assess the situation of postgraduates' self-satisfaction based on those factors.

\section{Methods}

Study design and participants. This cross-sectional study was based on an online questionnaire that was randomly distributed to postgraduates of medical majors in universities across China. The collected information included 1) demographic data; 2) guidance source, research platform and academic achievement of scientific research; 3) degree of time urgency, anxiety and depression; and 4) Likert-scale measurement of scientific self-satisfaction (from 0 to 10). In detail, age, marital status (Single, In love, Married, Child bearing), medical school year of training (First year vs Second year vs Third year vs Fourth 
year vs Deferment), major specialty (Internal Medicine vs Surgery vs Others), degree (Master candidate vs Doctor candidate) and degree category (Academic type vs Professional type) were considered sociodemographic characteristics. Objective factors included research category or direction (basic scientific research vs clinical scientific research), university type (from "double world-class" university or not), university location, research working time per day ( $1-3 \mathrm{~h}$ vs $4-6 \mathrm{~h}$ vs $7-9 \mathrm{~h}$ vs $10-12 \mathrm{~h}$ vs $\geq 13 \mathrm{~h}$ ), research learning manner (guided by mentor and others vs unguided or self-culture), number of published papers and participating projects. The degree of anxiety or depression as well as sense of time urgency were classified as subjective factors.

This study was registered on 1st November 2020 at the Chinese Clinical Trial Register, ChiCTR2000039574 (http://www.chictr.org.cn/searchproj.aspx), and approved on 9th November 2020 by the Medical Ethics Committee of Plastic Surgery Hospital, Chinese Academy of Medical Sciences and Peking Union Medical College, No. 2020157. All methods were performed in accordance with the relevant guidelines and regulations. A total of 1090 medical postgraduates answered voluntarily without compensation, and informed consent was obtained from all subjects. After postdoctoral and invalid questionnaire respondents were deleted, 1067 participants were studying for a medical degree, 810 for a master's degree and 257 for a doctoral degree.

Measures. Students' scientific self-satisfaction was estimated by an 11-point Likert self-rated scale with scores of " $0-11$ " representing degree from "strongly disagree" to "strongly agree". The sense of time urgency was estimated by a 7-point Likert self-rated scale, with scores of " $1-7$ " representing the degree from "strongly disagree" to "strongly agree". A Likert self-rated scale is a common form of self-rated questionnaire ${ }^{25-27}$. The cutoff for the score of postgraduates' academic satisfaction on scientific research was defined as low ( 0 to 4 points) and high (5 to 10 points).

Two self-report questionnaires, the 7-item Generalized Anxiety Disorder Scale (GAD-7) ${ }^{28,29}$ and the 9-item Patient Health Questionnaire (PHQ-9) ${ }^{30,31}$, were administered to the subjects to screen and determine the severity of the most common mental disorders, such as depression, anxiety and somatic illness, as recommended by the American Psychiatric Association (APA). Both show good reliability and score validity in the general population both in China and other countries ${ }^{32-34}$.

The GAD-7 is used to screen generalized anxiety and evaluate the severity of symptoms. It is divided into 7 items, with 0 to 3 grades, of which 0 is not at all, 3 is almost every day, with the lowest total score of 0 and the highest of 21 . The cutoffs for the GAD-7 scores were defined as minimal ( 0 to 4 points), mild ( 5 to 9 points), moderate (10 to 14 points) and severe (15 to 21 points) ${ }^{35}$.

The PHQ-9 is used to evaluate the severity of depression symptoms. It is divided into two parts. The first part is composed of nine depression symptoms. The second part has one item. The score is from 0 to 3 . Grade 0 means not at all, and grade 3 means nearly every day. The lowest total score is 0 , and the highest is 27. Depression symptoms according to PHQ-9 scores were defined as minimal (0 to 4 points), mild (5 
to 9 points), moderate (10 to 14 points), moderately severe (15 to 19 points) and severe (20 to 27 points) $)^{36}$.

Study variables and definitions. "Double world-class" university is a type of university with top ranking and word-class subjects. In 2015, the CPC Central Committee and the State Council announced the plan to coordinate and promote the construction of world-class universities and disciplines as a strategic decision to enhance China's competitiveness and lay the foundation for long-term development ${ }^{37,38}$. According to the new university ranking in this plan, universities pay more attention to cultivating the research innovation ability of medical students in affiliated hospitals, which helps them become class $A$ of China's "double world-class" university.

Degree categories of medical postgraduates include professional type and academic type, while degrees are divided into master and doctor. Professional masters have to complete hospital clinical standardized training and academic topics within three years under the "four certificates in one" training mode ${ }^{39}$. Academic masters are required to have a higher influence factor paper based on original scientific research for their graduation.

Research categories consist of basic science research, clinical science research, both basic science and clinical science research and uncertain research directions. Generally, basic science research requires researchers to spend much time in the lab and usually needs experimental platforms, sufficient research funds and professional guidance for experiments. The main work of clinical research is the collection and analysis of data from clinical patients.

Research learning methods are divided into unguided and self-cultural or guided by one's own professional mentor and others, including the associate supervisor, senior schoolmates or classmates. Research working time per day is divided into five intervals: $1-3 \mathrm{~h}$ vs. $4-6 \mathrm{~h}$ vs. $7-9 \mathrm{~h}$ vs. $10-12 \mathrm{~h}$ vs. $\geq 13 \mathrm{~h}$. Marital status includes single, in love, married without child bearing ("married" as abbreviation) and married and completed child bearing ("child bearing" as abbreviation).

Statistical analysis. Statistical analysis was performed using $\mathrm{R}$ version. For the goal-generating participants, descriptive statistics and univariate and multivariate analyses were performed, and receiver operating characteristic (ROC) curves were plotted to determine the correlation of characteristics with scientific self-satisfaction. Student's t tests were used to compare continuous variables, and Fisher exact tests were used for categorical variables. The valid variables were then included in a prediction model of the alignment diagram, which is also known as the nomogram, to predict academic satisfaction with scientific research. Significant differences were defined as $P<0.05$.

\section{Results}

\section{Basic characteristics of participants}


There were 1067 medical postgraduates collected. A total of them were pursuing a medicine degree, more than three-quarters for a master's degree $(41.1 \%$ for academic degrees and $34.8 \%$ for

professional degrees) and others for a doctoral degree (12.4\% for academic degrees and $11.7 \%$ for professional degrees) (Figure 1, A). Either master candidates or doctor candidates were in medical school year of training, including first year (40\%), second year (35.0\%), third year $(21.3 \%)$, fourth year (1.98) and during deferment (1.8\%) (Figure 1, B). More postgraduates came from 'double worldclass' universities than from other universities ( $75.7 \%$ vs. $24.3 \%$, respectively) (Figure $1, C)$, whereas a small subset of those universities were located in first-tier cities (22.9\%) (Figure 1, D), and nearly $36.1 \%$ of them were distributed in other-tier cities of Hunan Province (Figure 1, E). Most academic master candidates and doctor candidates considered themselves to research on basic science research $(57.1 \%$ and $41.6 \%$ ), followed by both clinical and basic science (22.6\% and $37.3 \%)$, clinical research ( $14.8 \%$ and $16.0 \%$ ) and uncertainty (5.5\% and $5.1 \%$ ), while the majority of professional master candidates were identified as engaging in clinical research (65.2\%) (Figure 1, F). The median respondent age was 25.5 years old (range: 18-44 years old). Over half of academic or professional masters were single ( $57.4 \%$ vs. $56.9 \%$, respectively), while only $28.0 \%$ doctor candidates were single (Figure $1, \mathrm{G}$ ).

\section{Low and high academic satisfaction and associated factors}

The percentage of each academic satisfaction score among different medical postgraduates of academic masters, professional masters and doctor candidates is shown in Figure 2. The mean scores were 4.43, 3.70 and 4.65, respectively, according to the 11-point Likert self-rated scale with scores of "0-10" (Table 1). The low (0 to 4 points) and high (5 to 10 points) types of satisfaction differed significantly among different postgraduates $(p<0.05)$ (Table 2$)$. The number of professional master candidates who have only participated in one science project is proximately equal to those without any project, and approximately four-fifths of both master candidates have not published papers as first or co-first authors. For doctor candidates, more participating projects or published papers are associated with higher satisfaction. Most master's or doctoral candidates have mild to serious anxiety and depression and could influence the degree of academic satisfaction. The self-rated time urgency sense score was $5.45 \pm 1.67$. These results can be found in Supplementary Tables S1-3.

In the next analysis, the master candidates and doctor candidates are viewed as a whole body. The pvalue of two-two factors is shown (Figure 3). Academic satisfaction is associated with GAD-7, PHQ-9, research learning manner, number of participating projects or published papers, research time per day and marital status. However, the "double first-class" university, the category of scientific research and the sense of time urgency are less prominently linked. Moreover, GAD-7 has a strong association with PHQ-9. Academic postgraduates tend to publish more papers than professional postgraduates and spend more time on research per day. The correction analysis revealed that second- or third-

grade postgraduates were sensitive to lower academic satisfaction ( $O R=1.95,95 \%$ confidence interval $[\mathrm{Cl}]=1.41-2.71, \mathrm{P}<0.001$ and $\mathrm{OR}=1.53,95 \% \mathrm{Cl}=1.06-2.23, \mathrm{P}=0.024$, respectively) (Figure 4). In terms of research learning manner, unguiding was another important risk factor for lower academic satisfaction $(\mathrm{OR}=1.88,95 \% \mathrm{Cl}=1.42-2.5, \mathrm{P}<0.001)$. Figure 4 also shows that research working time per day, such as 
4 6 hours $(\mathrm{OR}=0.60,95 \% \mathrm{Cl}=0.40-0.90, \mathrm{P}=0.013)$ or $10-12$ hours $(\mathrm{OR}=0.52,95 \% \mathrm{Cl}=0.32-0.82$, $\mathrm{P}=0.006$ ), rather than 1-3 hours or $\geq 13$ hours, was related to a higher degree of selfsatisfaction. Postgraduates who fall in love $(\mathrm{OR}=0.72,95 \% \mathrm{Cl}=0.54-0.97, \mathrm{P}=0.030)$ or are married and child bearing $(\mathrm{OR}=0.57,95 \% \mathrm{Cl}=0.33-0.96, \mathrm{P}=0.036)$ tend to have high academic self-satisfaction. Along with the severity of anxiety and depression, it is more likely related to lower satisfaction. In contrast, taking part in science projects contributes to improving the degree of satisfaction ( $P=0.004)$. When we only analyzed master candidates, the associations were roughly aligned with the whole body illustrated before (see Supplementary Table S1, S2 online). However, there was another protective factor, the number of papers published $(P=0.003)$.

\section{A novel model to assess satisfaction based on postgraduate characteristics}

We then published a nomogram as a novel predictive model based on these valid variables (Figure 5A). The ROC curve for academic satisfaction is shown in Figure 5B. We identified several corresponding risk or protective factors. Scientific satisfaction could be influenced by medical school years of training, research working time per day, number of participating projects, marital status, research learning manner, degree of anxiety (GAD-7) and depression (PHQ-9). First, for the model of characteristics with scientific time urgency, the overall AUC for ROC curves was 0.73 , and the correct classification rate was $67.8 \%$, with an estimated sensitivity of $51.2 \%$ and a specificity of $81.2 \%$. The false positive rate was $31.1 \%$, the false negative rate was $32.8 \%$, and the goodness-of-fit test was 0.06 .

\section{Discussion}

This study surveyed 1067 medical postgraduates across China to explore whether students' academic satisfaction with scientific research could be affected by those characteristics, including sociodemographic characteristics (age, marital status, medical school year of training, major specialty, master's or doctoral degree and degree category of academic or professional), objective factors (research direction, from "double world-class" university or not, university location, research working time per day, research learning manner, number of published papers and participating projects), and subjective factors such as sense of time urgency, anxiety and depression. It was found that the majority of postgraduates come from "double world-class" universities. The median age of the participants was 25.5 years old, with nearly half of the respondents $(75.9 \%)$ being master candidates. The academic satisfaction score was lowest among medical professional masters and highest among doctor postgraduates, followed by academic masters. Research working time per day, number

of participating projects and research learning manner could affect academic selfsatisfaction. However, neither university type or location nor research direction appeared to be related to overall low satisfaction. Higher levels of depression and anxiety were associated with postgraduates' low satisfaction with scientific research, whereas the sense of time urgency was not affected.

\section{Academic satisfaction of scientific research among postgraduates and objective associated factors}


The outcome analysis suggested that postgraduates experienced moderate levels of selfsatisfaction. The professional masters performed the lowest level of satisfaction, possibly because they needed to balance the time properly between clinical standardized training and academic projects within three years under the "four certificates in one" training mode $^{39}$. Most professional masters research in the clinical science direction, while academic masters engage in basic science (Figure 1). Generally, clinical research requires the full collection and analysis of data from clinical patients, while basic science research requires researchers to spend much time in the lab with sufficient research funds as well as professional guidance for experiments. However, both usually need experimental platform. However, it does not show a significant distinction between research category and satisfaction. Doctor candidates who have the highest satisfaction may be due to their rich experience and skills in scientific research, which help them complete science projects and finish papers. In fact, most postgraduates without academic projects are in low medical school years, and they are less experienced.

Moreover, as noted in our study, the number of participating projects and mentors' guidance are critical to postgraduates' satisfaction with scientific research. Our analysis demonstrates that medical postgraduates participating in science projects showed higher satisfaction and spent more time on daily research activity than those without projects (Fig. 3). The number of projects is a protective factor for low academic satisfaction. However, in our study, more than one-fifth of master postgraduates had not taken part in any project, especially professional master candidates (Supplementary Tables S1, S2). Thus, medical postgraduates should be encouraged to join in sciences practice as soon as possible, which helps them accumulate rich operation experience. In the initial process of a project, the overriding aim is to inspire their interest and enthusiasm for scientific research. In terms of daily science hours, a number of master's students (34\%), especially professional students, spend 1 3 hours and show a lower level of academic satisfaction. It is interesting that properly increasing the daily time length for scientific research, such as 4 6 hours or 10-12 hours, contributes to improving the degree of self-satisfaction, while working times that are too short or too long have no contribution (Fig. 4). This is probably because time length in scientific research, as an indirect reflection of devotion to the research, is a necessary base for scientific achievement, while too longer working wears researchers and impairs the efficiency of research. Meanwhile, postgraduates who work longer per day are likely to obtain more papers (Fig. 3).

As one study indicated, almost $98 \%$ of participants identified lack of mentoring as the first (42\%) or second (56\%) most important factor hindering career progress in academic medicine ${ }^{40}$. Additionally, another study found that medical master postgraduates with mentors' guidance report more publications, but they focused on academic medicine faculty members rather than postgraduates 41,42 . However, our analysis shows that there is nonsignificant association between the number of published papers and guidance from mentors among all participants. Specifically, a significant association between papers and guidance is indicated among doctor candidates but not among master candidates (Supplementary Table S1-3). Moreover, approximately one-fifth of master respondents $(20.6 \%)$ were learning on their own, while most of them felt lower research satisfaction than those guided 
by formalized mentors, senior postgraduates, peers or colleagues. It is a major challenge for postgraduates to complete scientific research independently because they might be headed in the wrong direction and be more likely to experience psychological dilemmas, as we discussed before. It is hard for them to achieve progress on scientific research projects. Although students are supposed to cultivate their ability to self-learn, from the perspective of our participants, scientific research lacking mentoring may increase academic stress and decrease the opportunity to achieve academic advancement and research fund disparities.

Therefore, postgraduates' educational institutions should promote the relationships between mentors and students. The mentors not only help postgraduates to direct academic questions or research assignments properly but also motivate the mentees to accomplish their research and obtain achievements in a high standard. As another study said, the effective mentor knows the mentees well enough to envision possibilities by recognizing the potential of the mentees so that they encourage the students to reach their highest potentials ${ }^{40}$. Establish reward policies for prized mentors who have "clout," knowledge and are willing to provide both professional and personal support to mentees. Sufficient guidance from mentors would offer medical postgraduates more opportunity to gain progress in their scientific research and help to maintain their mental health. This, in turn, would contribute to improving the level of academic satisfaction and working out high-quality papers.

\section{The state quo of mental unhealthy and it relates to lower self-satisfaction}

When investigating postgraduates' academic satisfaction, we find that $76.0 \%$ of postgraduates have depression or depressive symptoms ( $16.6 \%$ serious) and $79.4 \%$ have anxiety ( $20.1 \%$ serious). As our study showed, depression and anxiety were associated with low satisfaction among postgraduates. Along with the severity of depression and anxiety, it is more likely to result in low satisfaction. Anxiety and depression are two unhealthy mental states. First, mental health has a further adverse impact on the physical and mental health of graduate students. For example, anxiety will significantly increase the risk of time urgency (Fig. 3). Some studies have reported that students suffering from depression tend to be despondent and lack interest or energy in activities. They usually have feelings of guilt or worthlessness and thoughts of suicide. In addition, these psychological symptoms suggest that postgraduates may be suffering from a huge gap between reality and expectation. Longterm anxiety or depression makes it more difficult for postgraduates to achieve the expected academic goals, which would wear down their confidence toward academia, finally resulting in low academic selfsatisfaction of scientific research. Meanwhile, students' intrinsic characteristics, such as time urgency, had a significant association with depression and anxiety (Fig. 3). Although no significant association was found in our study between time urgency and self-satisfaction, people with A-type personality tend to pursue perfection and have high requirements for themselves. They are usually

difficult to be satisfied, which increases the probability of anxiety or depression symptoms ${ }^{43,44}$.

Our survey suggests that there is a high prevalence of mental unhealth among medical postgraduates. However, one study found that only $36 \%$ of students with mental disorders see a mental health 
professional to address mental concerns ${ }^{5}$. This is because postgraduates might feel ashamed to consult psychological problems, and several academies do not have supporting measures to solve postgraduates' psychological problems. Thus, on the one hand, medical academies and affiliated hospitals should help students build a right attitude toward their mental health and encourage them to use counseling services without worrying about what others thought. In addition, when students feel stressful about their research, they are supposed to look to peers and colleagues for informal mentoring and assistance in navigating academic research. Colleague mentors can be found both in one's own department and at other academic centers. On the other hand, it is necessary for hospitals to develop and perfect mental and emotional support systems for their students, including support from teaching department tutors, developing counseling services and a third-party occupational health approach. This collaborative mentoring would offer an effective approach for students to balance their mental health. Meanwhile, a close network of families, friends, and community connections is highly valued in Chinese society, which is important for adolescents and young adults to resist and effectively cope with the stressful events related to mental health ${ }^{45}$. Moreover, individuals, especially those with type A characters, should avoid self-imposed pressures, such as setting the bar too high to reach and selfdoubt. Some of them may be undergoing intense competition against other prospective masters to apply for doctor education. In this case, they are supposed to improve their scientific research ability as well as mental toughness (MT) ${ }^{46}$. Regardless, making progress in scientific research requires effort and persistence rather than stress-related academic dishonesty ${ }^{47}$.

\section{A novel model to predict lower self-satisfaction based on associated factors and direct individualized interventions}

According to our survey, academic satisfaction with scientific research could be affected by many factors, including tutor guidance, the number of participating projects, anxiety and depression. Therefore, based on the results of multivariable logistic regression, we assigned a value to the contribution of those factors to satisfaction. When each score is summed, we can use the total grade to predict the level of academic satisfaction of medical postgraduates. In other words, we established a prediction model of the alignment diagram, which is also known as the nomogram. This novel prediction model for academic satisfaction of medical postgraduates is based on multiple related factors. Thus, it can screen according to the predicted value of scientific research satisfaction of medical research and help to direct early intervention to postgraduates with low satisfaction.

\section{Limitations Of The Study}

Although this study identifies various factors related to academic satisfaction with scientific research and offers some practical suggestions, there are three limitations. First, the study used an online survey to collect information. It is impossible to control the answering environment, and it may even be subject to deviations. The geographical distribution of the number of samples is not very reasonable because the data in our sample are mainly in several provinces. Meanwhile, if we increased the sample size, some factors that the association had no significant statistical meaning would be reversed. For example, an 
association between time urgency and satisfaction might be noted, as might the number of papers. Second, there is a lack of persuasive evidence to demonstrate the interaction mechanism by which depression or anxiety in postgraduates is associated with low satisfaction with scientific research because this is a cross-sectional investigation. Finally, we expect to design deeper studies to reveal more associated factors that help to improve the self-satisfaction of postgraduates. Overall, our investigation is a complement to the investigation on the state quo of academic satisfaction considering both intrinsic and extrinsic characteristics among professional and academic postgraduates, revealing factors associated with satisfaction.

\section{Conclusions}

This study found a high prevalence of low satisfaction among medical postgraduates. Depression or anxiety degree, nonguided research learning manner and irrational research working time per day were risk factors for low academic self-satisfaction in scientific research. Based on this finding, we recommend hospital administrators, policy makers, and nongovernmental organizations to establish mental health services at corresponding centers. Tutors should pay more concern to postgraduates' mental health and give students more guidance and support in their research projects. Moreover, public health professionals and experts need to design strategies for early screening of unsatisfaction to prevent unhealthy psychology, and management of risk-associated factors is crucial.

\section{Declarations}

\section{Acknowledgment:}

No

\section{Conflict of interest disclosures:}

None

\section{References}

1. Koçak, O. et al. The Role of Family Influence and Academic Satisfaction on Career Decision Making Self-Efficacy and Happiness. Int. J. Environ. Res. Public Health. 18, 5919; 10.3390/ijerph18115919 (2021)

2. M., T., H., R., M., M., \& M., A. The Relationship between Happiness and Academic Achievements. European Online Journal of Natural and Social Sciences: Proceedings. 4, 241-246 (2015).

3. Shanafelt, T. D. et al. Changes in Burnout and Satisfaction With Work-Life Balance in Physicians and the General US Working Population Between 2011 and 2014. Mayo. Clin. Proc. 90, 1600-1613 (2015).

4. Murray, A. et al. Doctor discontent. A comparison of physician satisfaction in different delivery system settings, 1986 and 1997. J. Gen. Intern. Med. 16, 452-459 (2001). 
5. Wilkes, C. et al. Wellbeing and mental health amongst medical students in Canada. Int. Rev. Psychiatry. 31, 584-587 (2019).

6. Shanafelt, T., \& Habermann, T. Medical residents' emotional well-being. Jama. 288, 1846-1847 (2002).

7. Oró, P. et al. Effectiveness of a Mindfulness-Based Programme on Perceived Stress, Psychopathological Symptomatology and Burnout in Medical Students. Mindfulness (N Y). 1-10; 10.1007/s12671-020-01582-5(2021).

8. Simpkin, A. L. et al. Assessment of Job Satisfaction and Feeling Valued in Academic Medicine. JAMA Intern. Med. 179, 992-994 (2019).

9. 㧩畈 (shuāng yiliú gāoxiào): First-class universities and disciplines of the world[N]. China Daily, http://www.chinadaily.com.cn/opinion/2016-07/04/content_25951654.htm (July 2016).

10. Zou, W. J., Zhang, S. Q., Wu, Q., \& An, Z. Y. The Satisfaction and Influencing Factors of the Research Capacity Training of the Postgraduate of Clinical Medicine in 8 Medical Colleges Under the "Twotrack Integration". Medicine and Society. 33, 125-129 (2020). (In Chinese)

11. Wolf, T. M. Stress, coping and health: enhancing well-being during medical school. Med. Educ. 28, 817; discussion 55-17 (1994).

12. Storrie, K., Ahern, K., \& Tuckett, A. A systematic review: Students with mental health problems-a growing problem. Int. J. Nurs. Pract. 16, 1-6 (2010).

13. Rotenstein, L. S. et al. Prevalence of Depression, Depressive Symptoms, and Suicidal Ideation Among Medical Students: A Systematic Review and Meta-Analysis. Jama. 316, 2214-2236 (2016).

14. Steptoe, A., Tsuda, A., Tanaka, Y., \& Wardle, J. Depressive symptoms, socio-economic background, sense of control, and cultural factors in university students from 23 countries. Int. J. Behav. Med. 14, 97-107 (2007).

15. Eisenberg, D., Gollust, S. E., Golberstein, E., \& Hefner, J. L. Prevalence and correlates of depression, anxiety, and suicidality among university students. Am. J. Orthopsychiatry. 77, 534-542 (2007).

16. Pratt, L. A., \& Brody, D. J. Depression in the U.S. household population, 2009-2012. NCHS. Data Brief. https://www.cdc.gov/nchs/data/databriefs/db172.pdf (Dec 2014).

17. Veal, C. T. We Burn Out, We Break, We Die: Medical Schools Must Change Their Culture to Preserve Medical Student Mental Health. Acad. Med. 96, 629-631 (2021).

18. Duffy, R. D., Borges, N. J., \& Hartung, P. J. Personality, Vocational Interests, and Work Values of Medical Students. Journal of Career Assessment. 17, 189-200 (2008).

19. Feather, N. T., \& Volkmer, R. E. Preference for situations involving effort, time pressure, and feedback in relation to type A behavior, locus of control, and test anxiety. J. Pers. Soc. Psychol. 55, 266-271 (1988).

20. Cole, S. R. et al. Time urgency and risk of non-fatal myocardial infarction. Int. J. Epidemiol. 30, 363369 (2001). 
21. Murphy, P. R., Boonstra, E., \& Nieuwenhuis, S. Global gain modulation generates time-dependent urgency during perceptual choice in humans. Nat. Commun. 7, 13526; 10.1038/ncomms 13526 (2016).

22. Altan-Atalay, A., Özarslan, I., \& Biriz, B. Negative urgency and time perspective: interactive associations with anxiety and depression. J. Gen. Psychol. 147, 293-307 (2020).

23. Myrtek, M. Type A behavior pattern, personality factors, disease, and physiological reactivity: A metaanalytic update. Personality and Individual Differences. 18, 491-502 (1995).

24. Stewart, S. M., Lam, T. H., Betson, C. L., Wong, C. M., \& Wong, A. M. A prospective analysis of stress and academic performance in the first two years of medical school. Med. Educ. 33, 243-250 (1999).

25. Fischer, D. et al. Capturing the patient's view of change as a clinical outcome measure. Jama. 282, 1157-1162 (1999).

26. Mahoney, S. T. et al. Practice Characteristics and Job Satisfaction of Private Practice and Academic Surgeons. JAMA Surg.156, 247-254 (2021).

27. Voutilainen, A., Pitkäaho, T., Kvist, T., \& Vehviläinen-Julkunen, K. How to ask about patient satisfaction? The visual analogue scale is less vulnerable to confounding factors and ceiling effect than a symmetric Likert scale. J. Adv. Nurs. 72, 946-957 (2016).

28. Herr, N. R., Williams, J. W., Jr., Benjamin, S., \& McDuffie, J. Does this patient have generalized anxiety or panic disorder?: The Rational Clinical Examination systematic review. Jama. 312, 78-84 (2014).

29. Löwe, B. et al. Validation and standardization of the Generalized Anxiety Disorder Screener (GAD-7) in the general population. Med. Care. 46, 266-274 (2008).

30. Manea, L., Gilbody, S., \& McMillan, D. Optimal cut-off score for diagnosing depression with the Patient Health Questionnaire (PHQ-9): a meta-analysis. Cmaj. 184, E191-196 (2012).

31. Adewuya, A. O., Ola, B. A., \& Afolabi, O. O. Validity of the patient health questionnaire (PHQ-9) as a screening tool for depression amongst Nigerian university students. J. Affect. Disord. 96, 89-93 (2006).

32. He, C. et al. The Accuracy of the Patient Health Questionnaire-9 Algorithm for Screening to Detect Major Depression: An Individual Participant Data Meta-Analysis. Psychother Psychosom. 89, 25-37 (2020).

33. Tibubos, A. N. et al. Is assessment of depression equivalent for migrants of different cultural backgrounds? Results from the German population-based Gutenberg Health Study (GHS). Depress Anxiety. 35, 1178-1189 (2018).

34. Levis, B., Benedetti, A., \& Thombs, B. D. Accuracy of Patient Health Questionnaire-9 (PHQ-9) for screening to detect major depression: individual participant data meta-analysis. Bmj. 365, I1476; 10.1136/bmj.I1476 (2019).

35. Spitzer, R. L., Kroenke, K., Williams, J. B., \& Löwe, B. A brief measure for assessing generalized anxiety disorder: the GAD-7. Arch. Intern. Med. 166, 1092-1097 (2006). 
36. Kroenke, K., Spitzer, R. L., \& Williams, J. B. The PHQ-9: validity of a brief depression severity measure. J. Gen. Intern. Med. 16, 606-613 (2001).

37. Peters, M. A., \& Besley, T. China's double first-class university strategy: 怄区. Educational philosophy and theory. 50, 1075-1079 (2018).

38. Yang, M., Leibold, J., Bodenhorn, T., Burns, J. P., \& Palmer, M. Building a "Double First-class University" on China's Qing-Zang Plateau: Opportunities, Strategies and Challenges. China Quarterly. 244, 11401159 (2020).

39. Shilin, F., Chang, G. A. O., Guanlin, L. U., Qiu, Z., \& Jing, L. I. U. The Investigation of the Training Model in "Four-in-One"Professional Master's Degree of Medicine. China Continuing Medical Education. 10, 34-37 (2018).

40. Jackson, V. A. et al. "Having the Right Chemistry": A Qualitative Study of Mentoring in Academic Medicine. Academic Medicine. 78 (2003).

41. Levinson, W. et al. Mentors and role models for women in academic medicine. West J. Med. 154, 423-426 (1991).

42. Ramanan, R. A. et al. Mentoring in medicine: keys to satisfaction. Am. J. Med. 112, 336-341 (2002).

43. Chang, E. C., Sanna, L. J., Chang, R., \& Bodem, M. R. A preliminary look at loneliness as a moderator of the link between perfectionism and depressive and anxious symptoms in college students: does being lonely make perfectionistic strivings more distressing? Behav. Res. Ther. 46, 877-886 (2008).

44. Guidi, J. et al. Subtyping depression in the medically ill by cluster analysis. J. Affect Disord. 132, 383388 (2011).

45. Xu, Q. et al. Perceived social support and mental health for college students in mainland China: the mediating effects of self-concept. Psychol. Health Med. 24, 595-604 (2019).

46. Lin, Y. et al. Mental Toughness and Individual Differences in Learning, Educational and Work Performance, Psychological Well-being, and Personality: A Systematic Review. Front Psychol. 8, 1345; 10.3389/fpsyg.2017.01345 (2017).

47. Rennie, S. C. et al. Differences in medical students' attitudes to academic misconduct and reported behaviour across the years-a questionnaire study. J. Med. Ethics. 29, 97-102 (2003).

\section{Tables}

Due to technical limitations, table 1 and 2 is only available as a download in the Supplemental Files section.

\section{Figures}




\section{A. Degree category}

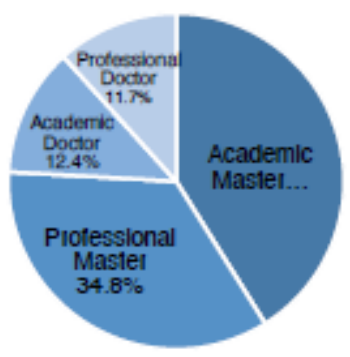

B. Medical school year of training

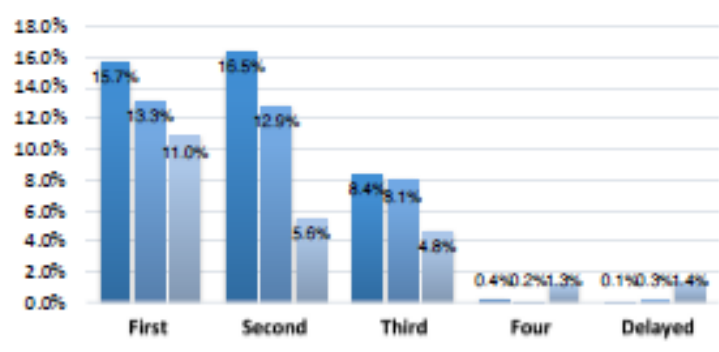

= Academic Master $=$ Professional Master $=$ Doctor
C. University type

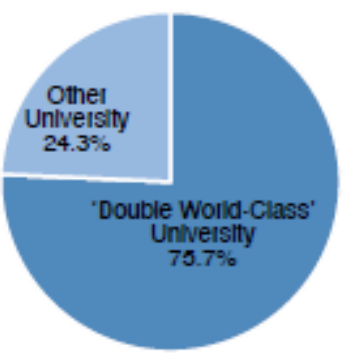

D. University location

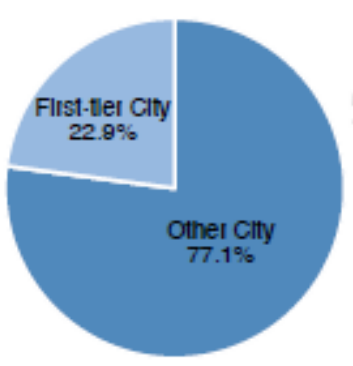

E. University distribution

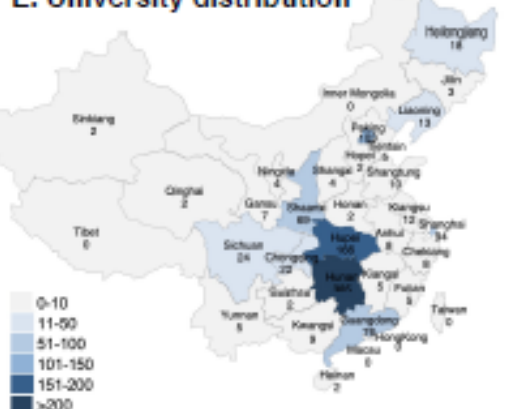

F. Research category

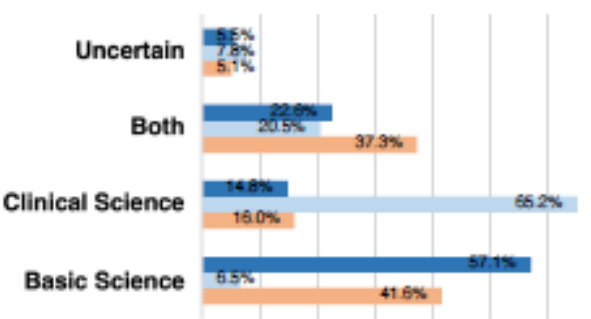

$0.0 \% 10.0 \% 20.0 \% 30.0 \% 40.0 \% 50.0 \% 60.0 \% 70.0 \%$
G. Marital status



- Academic Master $=$ Professional master $=$ Doctor

\section{Figure 1}

Characteristics of 1067 medical postgraduates in China. Charts showing (A) degree category, (B) medical school year of training, (C) university type, (D) university location, $(E)$ university distribution, $(F)$ research category and $(G)$ marital status. 


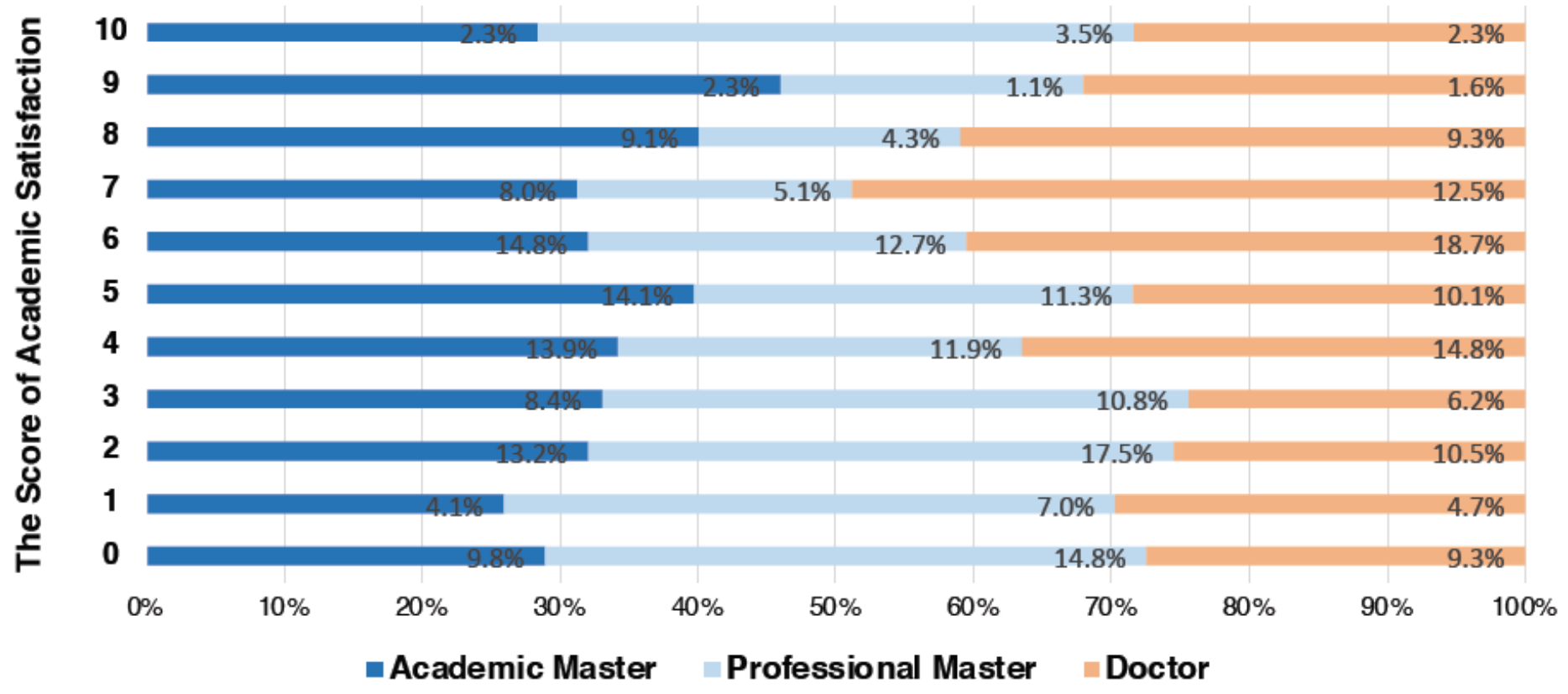

Figure 2

The percentage of each score (0-10) of academic satisfaction among academic master, professional master and doctor candidate 


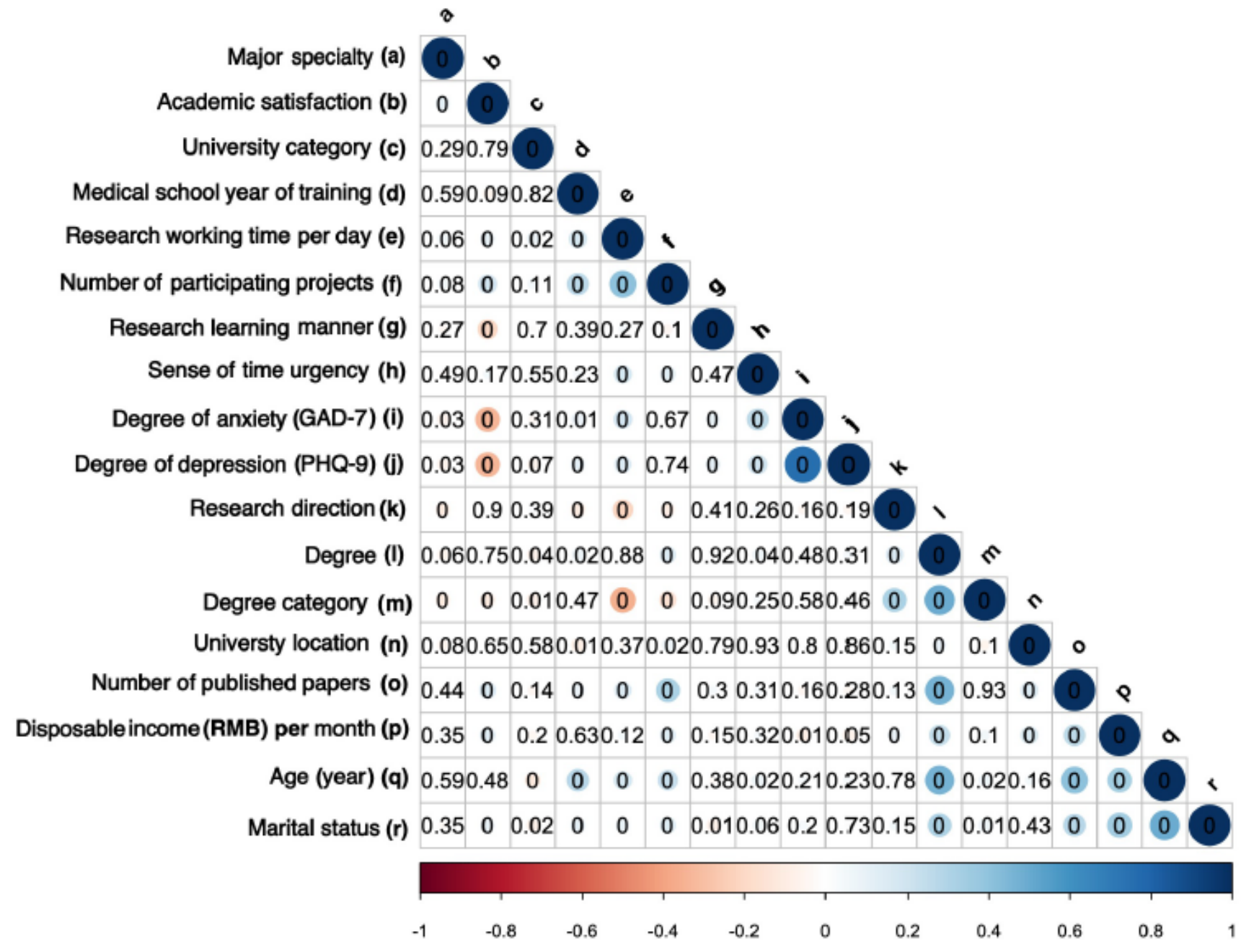

Figure 3

The correlation between each factors. The red represents a positive correlation while the blue represents a negative one. The number in bar represents a significant $p$-value. Lower-case letters represent the factors. 


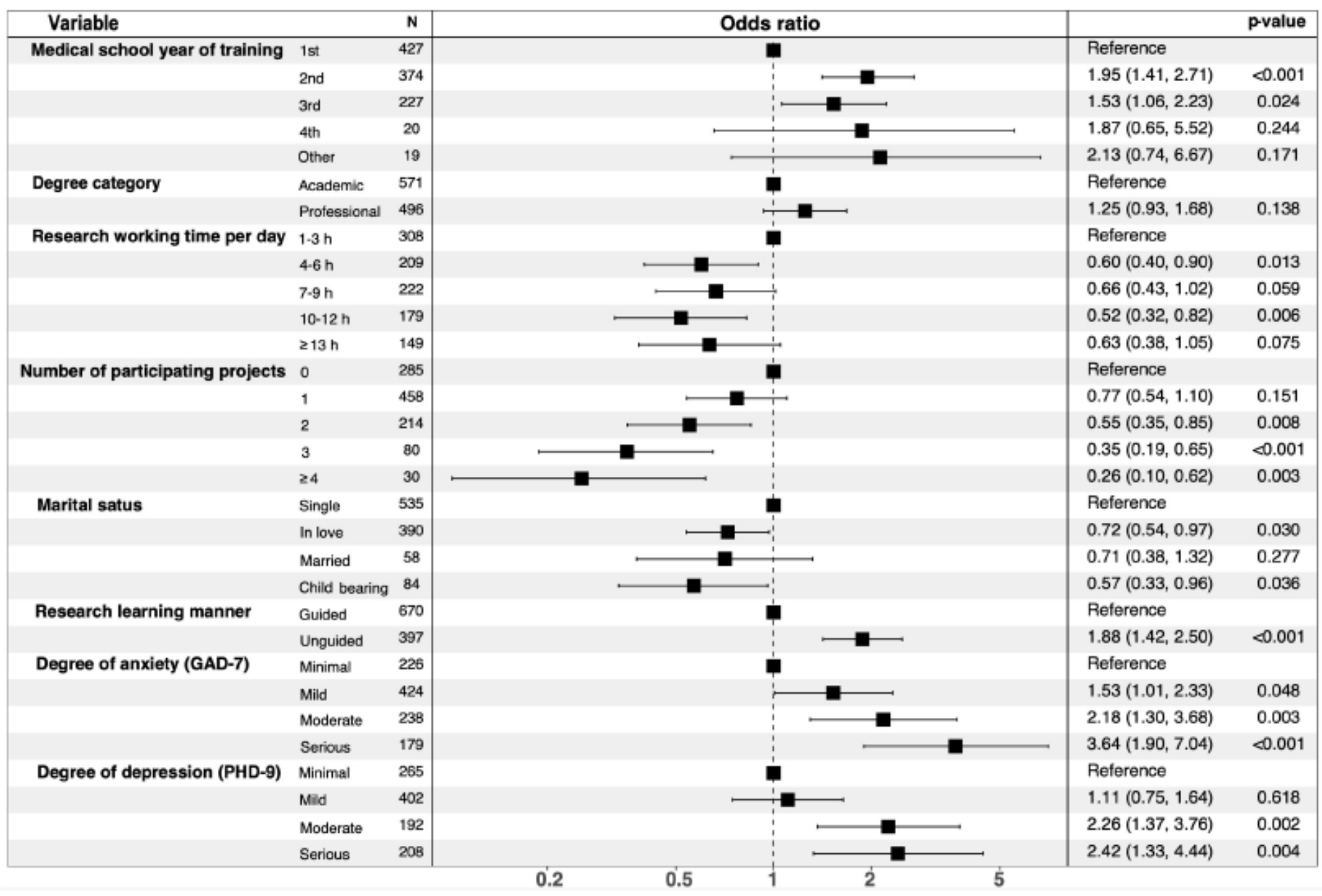

\section{Figure 4}

Forest plots depicting pooled multivariable predictors of low satisfaction. Plots display predictive probabilities of associated factors, corresponding 95\% confidence intervals (Cls). 
A.

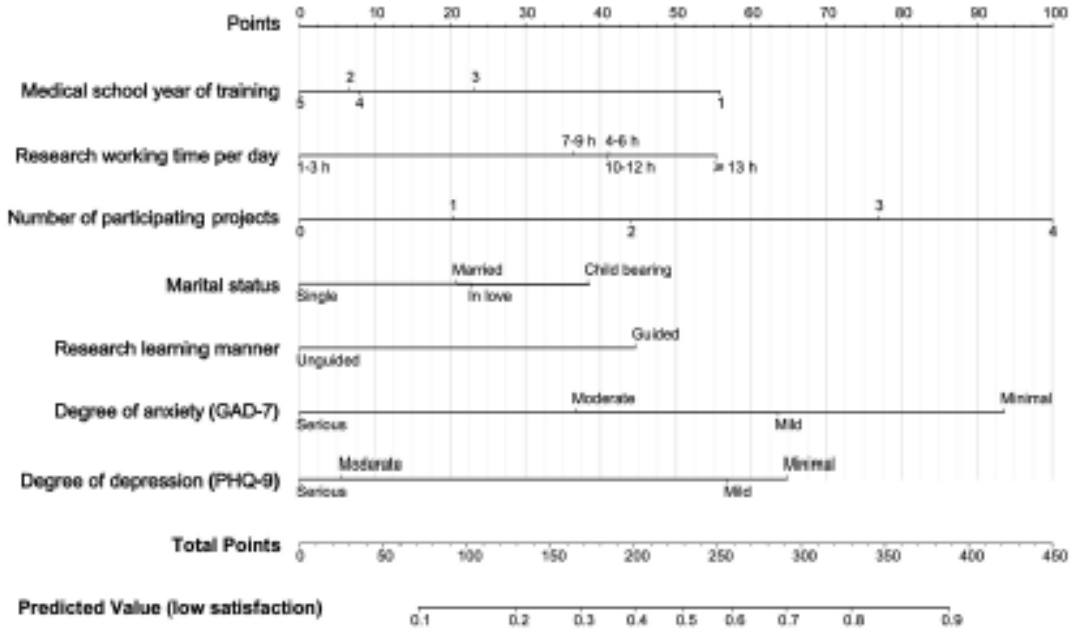

B.

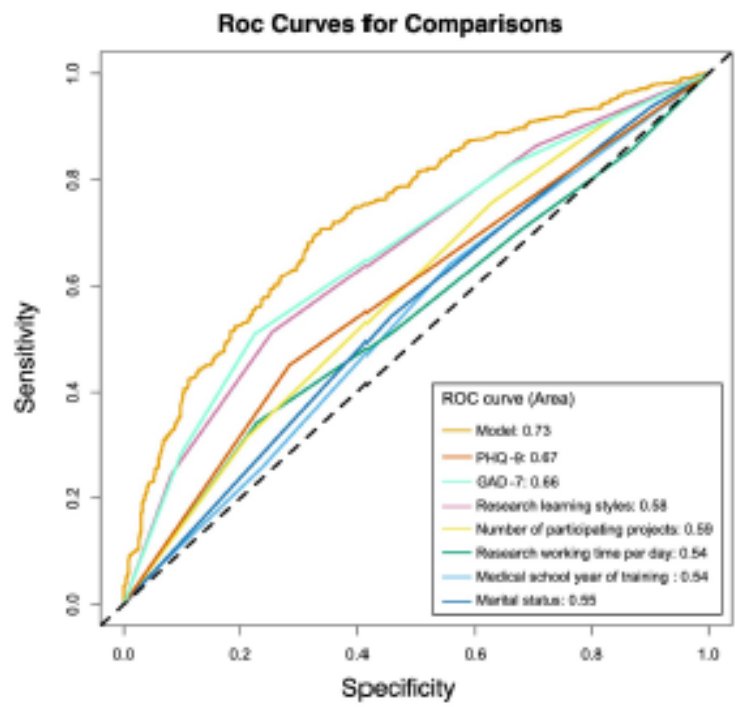

Figure 5

Instructions for using nomogram to predict low academic satisfaction and the corresponding ROC curves

\section{Supplementary Files}

This is a list of supplementary files associated with this preprint. Click to download.

- 2.TablesandFigures.pdf

- 3.SupplementaryTables.pdf 